\title{
Cotas tarifárias e o impacto sobre as exportações agrícolas brasileiras na União Européia ${ }^{1}$
}

\author{
Honório Kume* \\ Guida Piani** $^{* *}$ \\ Pedro Miranda**
}

Resumo: Este trabalho tem como objetivo avaliar os efeitos de cotas tarifárias adicionais para as exportações brasileiras de produtos agrícolas, com base na proposta européia de maio de 2004 no âmbito das negociações para um acordo de livre-comércio Mercosul- União Européia. A análise teórica do funcionamento dos três instrumentos da cota tarifária (seu volume e as tarifas intra e extracota) revela que, dependendo da demanda, apenas um deles efetivamente restringe as importações. Assim, a oferta de cotas adicionais não implica necessariamente um aumento equivalente na quantidade exportada. Na estimativa de ganho de receita deve ser considerada também a variação na renda da cota. Além disso, a administração da cota terá um papel crucial na alocação dessa renda. Caso seja o Mercosul a fazê-la, as estimativas indicam um aumento de US\$ 728 milhões na receita de divisas, bastante próximo do valor da cota total oferecida a preços correntes, sendo US $\$ 252$ milhões

\footnotetext{
${ }^{1}$ Versão revista do trabalho apresentado no XLIV Congresso da Sociedade Brasileira de Economia e Sociologia Rural (SOBER), Fortaleza, em julho de 2006, no ACRALENOS II SEMINAR "Agricultural Trade Liberalization and Developing Countries: Expected Consequences and Effective Impacts, 4 Critical Issues”, Santiago, em novembro de 2006 e no XXXIV Encontro Nacional de Economia (ANPEC), Salvador, em dezembro de 2006. Agradecemos os comentários e as sugestões dos participantes desses encontros e de dois pareceristas anônimos.

* Doutor em Economia pela USP, pesquisador do IPEA/RJ e Professor Adjunto da FCE/ UERJ. kume@ipea.gov.br

** Mestre em Economia pela PUC-Rio, pesquisadora do IPEA/RJ. guidapiani@ipea.gov.br *** Mestre em Economia pelo IE-UFRJ, pesquisador do IPEA/RJ. pmiranda@ipea.gov.br
} 
resultantes da apropriação das rendas das cotas e US\$ 476 milhões do incremento nas exportações. Se o controle das cotas for realizado pela União Européia, o ganho do Brasil decorrerá exclusivamente do aumento das exportações, atingindo apenas $63,7 \%$ do valor da cota citada.

Palavras-chave: cota tarifária, exportação, Mercosul

\section{Classificação JEL: Q17}

Abstract: This paper aims to evaluate the effects of additional tariff quotas on some Brazilian agricultural exports. The study focuses on the European offer in the negotiations for a Mercosur-European Union free trade agreement in May 2004. The economic analysis of the tariff quota shows that - given the demand curve - only one of the three components (the volume and the intra and extra tariffs rates) will effectively pose a restriction to the imports. So, the concession of an additional quota does not necessarily imply an equivalent increase in exports. In the estimation of the gains, one must consider the change in the quota rent. Besides the administration of the quota systems will play crucial role on the allocation of the quota rent. If Mercosur gets in charge, the estimates indicate an addition of US\$ 728 million in exports, of which US\$ 525 million result from the appropriation of the quota rents and US\$ 476 million from exports. The sum of both is indeed close to the value of the additional quotas at current prices. If the administration goes to the EU, the gains will derive exclusively from the expansion in exports, which corresponds to $63.7 \%$ to the value of the quota.

Key words: tariff rate quotas, exports, Mercosur.

\section{JEL Classification: $Q 17$}

\section{Introdução}

Ao longo das últimas décadas, o protecionismo e as práticas discriminatórias têm sido as características mais marcantes do comércio internacional de produtos agrícolas. Os governos dos países desenvol- 
vidos, em especial, têm recorrido intensamente a medidas como subsídios domésticos, subsídios às exportações e restrições às importações, tanto na forma de barreiras não-tarifárias como através de tarifas extremamente elevadas.

Algumas tentativas de reformas dessas políticas, em âmbito multilateral, já haviam sido realizadas em rodadas de negociações do Acordo Geral de Tarifas e Comércio - General Agreement on Tariffs and Trade (GATT) - anteriores à Rodada Uruguai, mas os resultados foram insignificantes, particularmente do ponto de vista dos países em desenvolvimento.

Em 1995, o Acordo sobre Agricultura da Rodada Uruguai - Uruguay Round Agreement on Agriculture (URAA) - conseguiu estabelecer regras destinadas a melhorar as condições de acesso ao mercado internacional de produtos agrícolas. Em sua maior parte, as restrições não-tarifárias incidentes sobre esses bens foram substituídas por tarifas. Além disso, foram criadas cotas tarifárias - tariff rate quotas (TRQs) - que permitem importações a tarifas mais baixas (tarifa intracota) dentro de uma quantidade especificada (cota), e importações adicionais a tarifas mais altas (tarifa extracota).

Desde então, o uso de cotas tarifárias disseminou-se tanto como parte dos compromissos assumidos no acordo implementado pela Organização Mundial de Comércio (OMC), como em vários acordos bilaterais ou regionais, graças à garantia de acesso a exportações agrícolas e à obtenção de rendas extraordinárias geradas pela imposição de cotas.

No entanto, o papel da cota tarifária como instrumento de proteção, principalmente nas negociações comerciais, ainda não é bem compreendido, pois muitas vezes ignora-se que apenas um dos três instrumentos da cota tarifária, dependendo da demanda, efetivamente restringe as importações, sendo os demais redundantes. Além disso, não se considera a importância do método de administração das cotas, o que é fundamental para definir a apropriação das rendas por elas geradas, cujo valor pode, em alguns produtos, superar o próprio montante das exportações.

Este trabalho pretende avaliar os possíveis efeitos da aceitação de cotas tarifárias pelos países do Mercosul para as exportações brasileiras de determinados produtos agrícolas destinados ao mercado da União Européia (UE), com base na última proposta oficial de maio de 2004, no âmbito das negociações para um acordo de livre-comércio. 
Além desta breve introdução, o trabalho é dividido em três seções. Na seção 2, após um retrospecto da criação e difusão de cotas tarifárias a partir de meados da década de 1990, serão apresentadas uma análise teórica do funcionamento desse instrumento de política comercial e uma avaliação dos seus efeitos econômicos. Na seção 3, a oferta de cotas adicionais para os produtos sujeitos à cota tarifária feita pela UE será usada para ilustrar os ganhos que se poderiam esperar nas exportações brasileiras. A seção 4 resume as conclusões.

\section{Cotas tarifárias}

\subsection{Breve histórico}

Nas primeiras negociações feitas pelos países-membros do GATT (1937, 1949, 1951 e 1956) para a liberalização do comércio agrícola mundial, quase nada foi alcançado. Na Rodada Kennedy (1962-1967), as negociações sobre o tema, entre os Estados Unidos e a Comunidade Européia, culminaram com a assinatura do Acordo Internacional sobre Grãos (comércio de trigo e ajuda alimentar). A Rodada Tóquio (19731979) produziu alguns acordos sobre o comércio de bens agrícolas de zonas temperadas e acordos bilaterais para a redução das tarifas de alguns produtos, mas os subsídios agrícolas continuaram sem definição específica e não houve compromissos para a sua redução. A Fórmula Suíça, aplicada para reduções de tarifas de produtos industriais, não foi utilizada para produtos agrícolas.

Da Rodada Uruguai (1986-1994), surgiu o primeiro acordo sobre agricultura, estruturado em dois eixos: a consolidação de tarifas no lugar de barreiras não-tarifárias e a instituição de cotas tarifárias.

Com o intuito de tornar as regras relativas ao comércio agrícola mais compatíveis com as que incidiam sobre os bens industrializados, os negociadores concordaram em substituir todas as restrições não-tarifárias - à exceção das medidas de caráter de segurança sanitária - por tarifas ad valorem ou específicas ou uma combinação delas. Nesse processo, conhecido como tarifação, as novas tarifas foram fixadas em níveis equivalentes à relação entre os preços domésticos e internacionais, tendo como referência o período 1986-1988. Dado o elevado nível de proteção vigen- 
te, os equivalentes tarifários resultantes foram bastante altos, alguns superiores a $150 \%$, como no caso de grãos na UE. Apesar do compromisso assumido pelos países desenvolvidos com um cronograma de reduções tarifárias, de em média $36 \%$ durante os seis anos seguintes, a adoção do sistema de cortes pelas médias ${ }^{2}$ permitiu a manutenção de tarifas especialmente elevadas para os produtos considerados mais "sensíveis". ${ }^{3}$

A segunda importante alteração introduzida pelo URAA foi a instituição de cotas tarifárias, com o objetivo de assegurar um patamar mínimo de acesso aos mercados agrícolas dos países desenvolvidos. Nesse sentido, foram criadas duas categorias de cotas tarifárias. Na primeira delas, conhecida como cotas de acesso mínimo, as tarifas deveriam ser suficientemente baixas, de forma a impedir que o processo de tarifação virtualmente bloqueasse as oportunidades comerciais para certos produtos. Às importações deveria ser franqueada uma participação equivalente a $3 \%$ do consumo doméstico, tomando por base o período $1986-1988 .{ }^{4} \mathrm{~A}$ segunda categoria, denominada cotas de acesso corrente, deveria garantir a preservação de níveis de acesso a mercado para determinados produtos, historicamente estabelecidos pelas quantidades previamente importadas.

Dadas as possibilidades de apropriação das rendas extraordinárias das cotas tarifárias, associadas ao seu volume e ao diferencial de tarifas intra e extracota, sua forma de administração desempenha um papel fundamental.

Freqüentemente, são usadas licenças de importação, alocadas às firmas importadoras ou às exportadoras ou a ambas, por meio de vários métodos, entre os quais se destacam: o de tarifas aplicadas - em que, levando-se em conta o preço e a tarifa intracota, a demanda por importações é inferior ao volume estipulado da cota, tornando a restrição quantitativa redundante -, o método de ordem de chegada (first-come, first-served) - em que as importações podem beneficiar-se da tarifa intracota até o momento de seu preenchimento -, o de licenças sob de-

\footnotetext{
${ }^{2}$ Considere dois bens com tarifas de, respectivamente, $1 \%$ e $100 \%$. Uma redução média nas tarifas de $36 \%$ pode ser obtida com as novas tarifas de $0,43 \%$ e $85 \%$. No entanto, a tarifa média passou de $50,5 \%$ para $42,7 \%$, equivalente a uma diminuição de apenas $15,5 \%$ na tarifa média.

${ }^{3}$ Além dos picos tarifários, o processo de tarifação preservou a chamada "escalada tarifária”, pela qual as tarifas dos produtos processados foram mantidas em níveis muito superiores aos de seus insumos.

${ }^{4}$ Essa proporção deveria crescer para 5\%, por volta de 2000 .
} 
manda - concedidas de acordo com a evolução do preenchimento da cota, em um dado período -, o de leilão e o de desempenho passado (SKULLY, 2001; GORTER; HRANAIOVA, 2004).

Entre 1995 e 2002, entraram em vigor 1.425 cotas tarifárias, como resultado do URRA ${ }^{5}$. Por categoria de produto, a maioria das cotas tarifárias é aplicada a frutas e vegetais (370 cotas tarifárias), carnes (258) e cereais (226). A UE (15 países) e os Estados Unidos são usuários relativamente importantes, aplicando, respectivamente, 87 e 54 cotas tarifárias. Entretanto, os países que mais utilizam esse instrumento de política comercial são Noruega (232) e Polônia (109). (GORTER; INGCO; IGNACIO, 2004)

O método de administração mais utilizado é o de tarifas aplicadas ${ }^{6}$, incidindo sobre mais da metade do total aplicado, seguido pelo de licenças sob demanda, pelo de ordem de chegada e pelo de desempenho histórico. O sistema de leilão, que provavelmente geraria uma alocação mais eficiente e permitiria ao governo apropriar-se da renda da cota, representa menos de $4 \%$ do total.

\subsection{Análise econômica da cota tarifária}

As cotas tarifárias sujeitam as importações a uma tarifa geralmente reduzida (tarifa intracota) até uma quantidade previamente fixada (cota) e a uma tarifa em geral bastante elevada (tarifa extracota), para a quantidade que ultrapassa a cota. Assim, uma cota tarifária baseia-se em três instrumentos: cota e tarifas intra e extracota. No entanto, dependendo da demanda de importações, apenas um deles exerce o controle efetivo das importações, sendo os demais redundantes (SKULLY, 2001). Assim, nas negociações comerciais para ampliação do acesso a mercado de produtos sujeitos a cotas tarifárias, é importante verificar qual desses instrumentos é efetivamente atuante, a fim de evitar demandas com impacto nulo sobre as exportações.

\footnotetext{
${ }^{5}$ Uma pequena parcela das cotas tarifárias pode ser atribuída aos novos membros da OMC, que tiveram de implementá-las para serem aceitos na organização.

${ }^{6}$ Nesse caso, conforme será demonstrado na seção seguinte, a importação é controlada pela tarifa intracota, sendo a cota e a tarifa extracota redundantes. Esse resultado pode ser decorrente de mudanças significativas no preço e/ou na demanda. No entanto, a explicação mais aceitável é a de que as cotas tarifárias foram estabelecidas como medida de precaução contra eventuais aumentos nas importações, que poderiam ser limitadas sem a necessidade de oferecer compensações equivalentes, como as exigidas no caso de medidas de salvaguardas.
} 
A Figura 1 ilustra três casos possíveis de restrições resultantes da adoção de cotas tarifárias para um determinado país importador pequeno. $P_{1}$ representa o preço de importação de livre-comércio, QT a cota, $M$ a quantidade importada, $T_{I}$ a tarifa intracota, $T_{E}$ a tarifa extracota, e $D$ a curva de demanda de importações. As importações até a quantidade QT são tributadas por $T_{I ;}$ e a quantidade excedente à $Q T$, por $T_{E}$.

Na parte (a), a demanda é $\mathrm{D}$, e a quantidade importada $\mathrm{M}$, ao preço $\mathrm{P}_{2}$, é inferior à quantidade fixada pela cota. Logo, a restrição às importações é dada pela tarifa intracota, enquanto a cota e a tarifa extracota são redundantes. O governo obtém uma receita tributária baseada na tarifa intracota cobrada nas importações M. Assim, uma expansão das importações ocorre somente com a redução da tarifa intracota.

Figura 1 - Restrições às importações com cotas tarifárias por tarifa intracota (a), cota (b), e tarifa extracota (c)

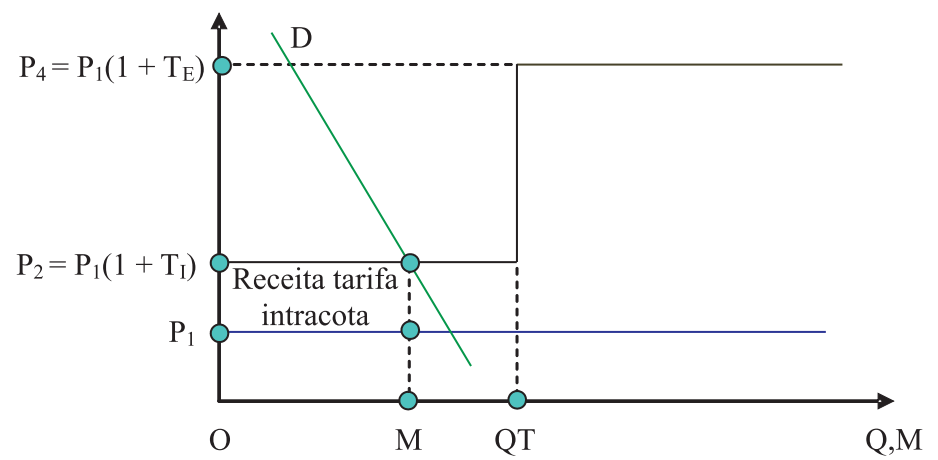

(a)

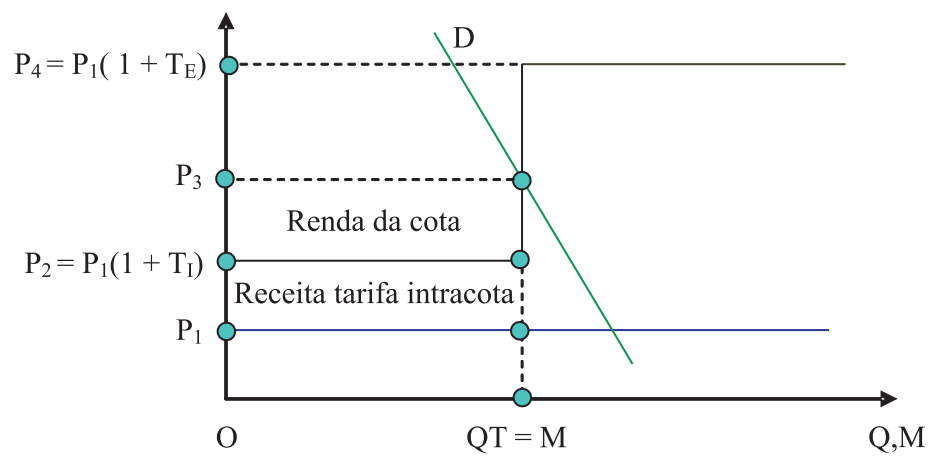

(b) 


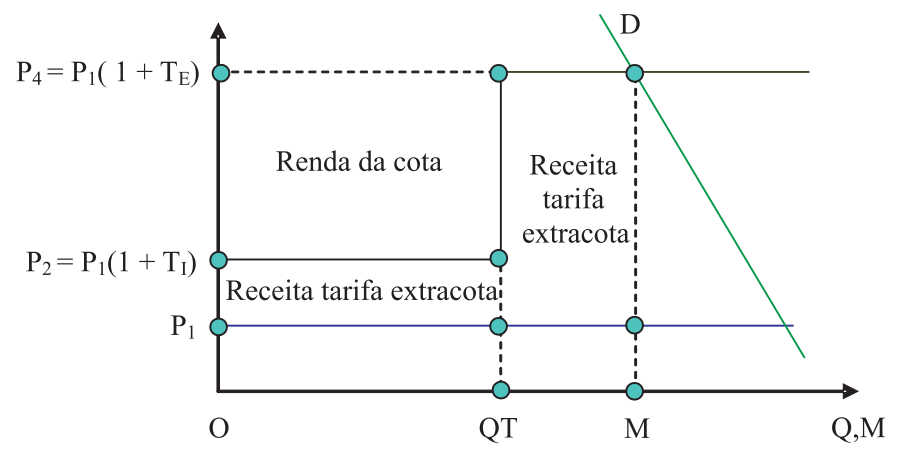

(c)

Fonte: Skully (2001)

Na parte (b), a demanda é $\mathrm{D}$, e a quantidade importada $\mathrm{M}$ é exatamente igual à quantidade estabelecida pela cota. Esta, portanto, limita as compras externas, e o nível de proteção varia entre as tarifas intra e extracota, devendo ser medido através da comparação entre o preço interno $P_{3}$ e o preço externo $P_{1}$. A renda da cota é representada pela área do retângulo formado por $P_{3-} P_{2}$ (diferença entre o preço no mercado doméstico do país importador e o preço pago nas importações, inclusive a tarifa intracota), multiplicada pelo volume da cota. Podemos notar que a renda da cota às vezes é tão importante quanto o valor das exportações.

Por fim, na parte (c), a demanda $D$ é suficientemente elevada para permitir importações acima da cota, gerando uma quantidade importada $M$ maior que a estabelecida pela cota. Nesse caso, o controle das importações é determinado pela tarifa extracota. O preço no mercado interno $P_{4}$ é determinado pelo preço $P_{1}$ acrescido da tarifa extracota. A renda extraordinária é dada pela diferença entre o preço interno $P_{4}$ e o preço de importação, inclusive a tarifa intracota, $P_{2}$, multiplicada pela quantidade $Q T$. O governo arrecada uma receita tributária decorrente da diferença entre $P_{2}$ e $P_{1}$, incidente sobre as importações intracota, e entre $P_{4}$ e $P_{1}$, incidente sobre as importações acima da cota (M-QT).

O critério adotado para a distribuição dos direitos à importação até o montante fixado pela cota define a distribuição da renda entre os países exportador e importador e entre os agentes econômicos e o governo em cada país. Se a administração da cota é feita pelo país importador (exportador), a renda é apropriada pelos importadores (exportadores). No 
país, se a cota é leiloada de forma competitiva, a renda da cota é transferida ao governo mediante o pagamento de ágios oferecidos para obter a licença de importação, enquanto, se outros métodos de administração são aplicados, os agentes privados capturam a renda extraordinária.

Assim, nas negociações comerciais que têm como um dos objetivos a ampliação das receitas em divisas, o país exportador deverá assegurar para si a administração da cota e solicitar um maior acesso ao mercado, observando o instrumento que efetivamente limita as suas exportações: redução da tarifa intracota, se as importações atuais são inferiores à cota atual; elevação da cota, se as importações são iguais à cota; e diminuição da tarifa extracota, se as importações excedem a cota vigente.

\subsection{Efeitos de uma cota adicional}

Nas negociações de acesso a mercado, uma proposta comum para os produtos agrícolas considerados mais sensíveis tem sido a oferta de cotas adicionais, seja de caráter temporário e crescente até a sua extinção, como a oferecida pelos Estados Unidos ao Chile no acordo de livre-comércio assinado recentemente entre ambos (U , 2003), ou, de forma permanente e sem aumentos de quantidades predeterminados, como a proposta européia nas negociações com o Mercosul (KUME et al., 2004).

Assim, nessa subseção, serão analisados, sob a ótica do país exportador, os efeitos de um aumento nas cotas no país importador, sobre as exportações e a renda da cota, nos três casos citados. Para simplificar a análise, será adotada a hipótese de que a cota é administrada pelo país exportador.

a) Importações iniciais inferiores à cota

Nesse caso, conforme visto anteriormente, o controle das importações é exercido pela tarifa intracota, sendo a cota e a tarifa extra redundantes. Portanto, uma oferta de cota adicional não afeta as exportações.

b) Importações iniciais equivalentes à cota

Nesse contexto, uma cota adicional gera um aumento equivalente nas exportações de $Q T_{1}$ para $Q T_{2}$ e reduz o preço doméstico de $P_{3}$ para $P_{5}$ (Figura 2). O incremento no valor das exportações é igual à 
cota adicional multiplicada pelo preço $P_{1}$. A redução do preço de $P_{3}$ para $P_{5}$ diminui a renda anteriormente proporcionada pela cota. No entanto, a cota adicional gera ainda uma renda extra equivalente à cota adicional multiplicada pela diferença entre o preço $P_{5}$ e o preço com tarifa intracota, $P_{1}\left(1+T_{T}\right)$. Portanto, o resultado líquido para o país exportador depende do ganho no valor da exportação e da renda extraordinária líquida. ${ }^{?}$

Figura 2 - Efeito de uma cota adicional: importações iniciais iguais à cota

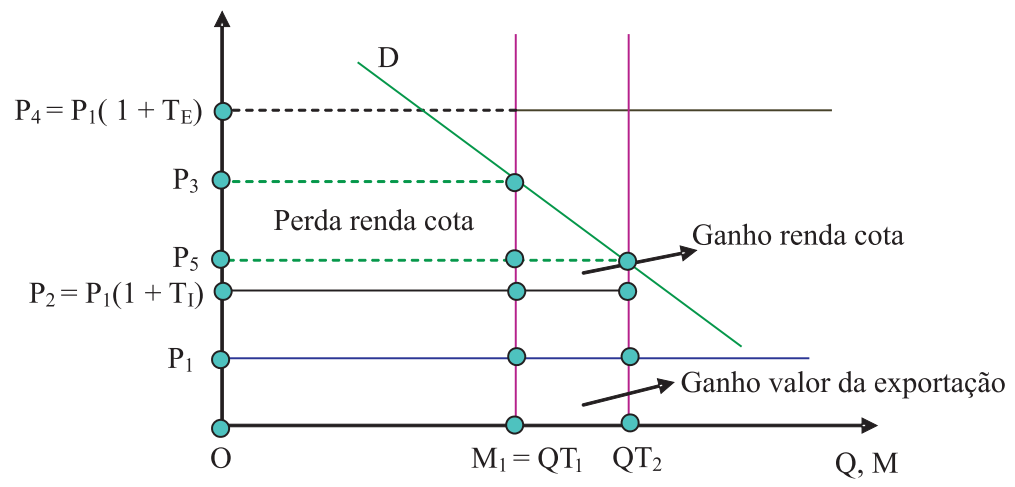

Fonte: Elaboração própria

Vale destacar que, para o país exportador, não existe distinção entre o valor obtido em dólares na exportação e o recebido via renda da cota.

c) Importações iniciais superiores à cota

Essa situação pode ser dividida em dois casos: se a cota adicional é inferior às importações extracota ou se é superior.

A oferta de um incremento na quantidade da cota inferior às importações extracota não altera a quantidade total demandada, ocorrendo apenas uma substituição parcial das importações extracota pela cota adicional. O ganho do país exportador será unicamente devido à apropriação da renda extraordinária, proveniente dessa cota adicional (Figura 3).

${ }^{7}$ A variação na renda extraordinária depende da elasticidade-preço da demanda. 
Figura 3 - Efeito de uma cota adicional inferior às importações extracota

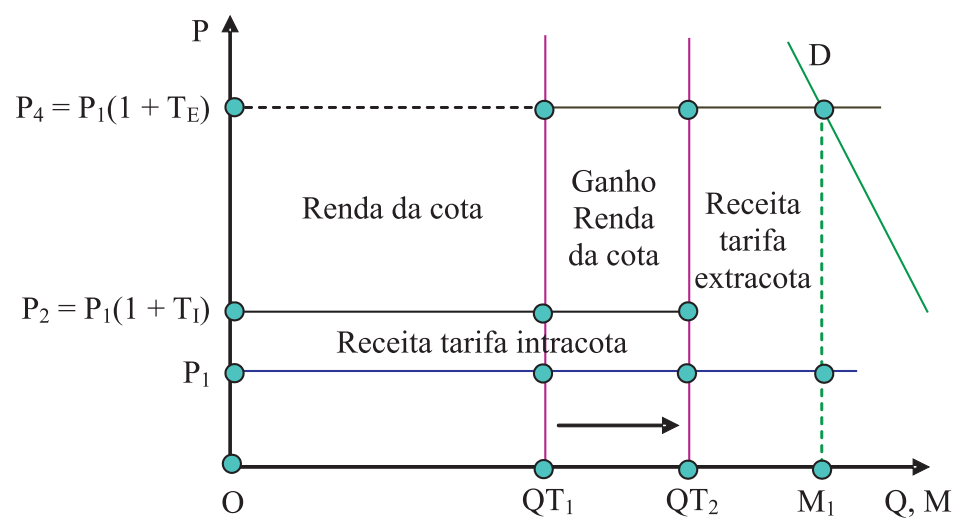

Fonte: Elaboração própria

Uma cota adicional $\left(\mathrm{QT}_{2}-\mathrm{QT}_{1}\right)$ maior do que as importações extracota $\left(\mathrm{M}_{1}-\mathrm{QT}_{1}\right)$ provocará uma queda no preço de $\mathrm{P}_{4}$ para $\mathrm{P}_{5}$ (Figura 4). A perda parcial da renda da cota anterior $\left(Q T_{1}\right)$ pode ser medida pela diferença entre $P_{4}$ e $P_{5}$, multiplicada por $Q T_{1}$. A nova cota gera uma renda equivalente à diferença entre $P_{5}$ e $P_{2}$, multiplicada pela cota adicional. $\mathrm{O}$ aumento no valor das exportações será igual à quantidade adicional exportada $\left(M_{2}-M_{1}\right)$, multiplicada pelo preço $P_{1}$. Novamente, o resultado líquido pode ser positivo ou negativo, dependendo do valor dessas áreas.

Figura 4 - Efeito de uma cota adicional superior às importações extracota

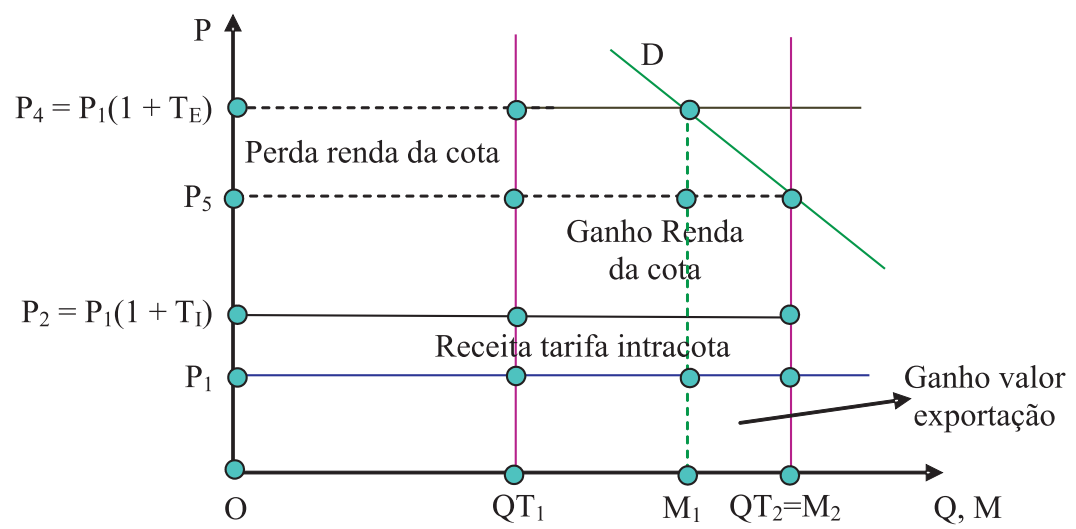

Fonte: Elaboração própria 


\section{Efeitos de uma cota adicional: uma aplicação}

A UE, um dos mais importantes mercados de exportação para os produtos agrícolas do Mercosul, adota cotas tarifárias para muitas dessas commodities. Em virtude disso, as eventuais concessões por parte dos europeus nessa área devem ser avaliadas de acordo com os parâmetros observados anteriormente. A oferta de cotas adicionais para determinados produtos agrícolas feita pelo bloco europeu em maio de 2004, no contexto de um futuro acordo de livre-comércio Mercosul-UE, será utilizada como ilustração para estimar os possíveis impactos sobre algumas exportações agrícolas brasileiras.

\subsection{A oferta da União Européia}

As negociações para um acordo de livre-comércio entre o Mercosul e a UE começaram ainda na primeira metade da década de 1990. Após um período de arrefecimento, as negociações foram retomadas e, em maio de 2004, foi feita uma troca formal de propostas entre os futuros sócios, com expectativa de conclusão do acordo até outubro daquele ano, quando se encerravam os mandatos dos comissários europeus. Entretanto, as divergências entre os dois blocos não foram superadas, e a meta anteriormente estabelecida não foi atingida.

De acordo com a oferta de maio de 2004, o número de produtos negociados atingia 10.427 - produtos da classificação a oito dígitos da Nomenclatura Combinada da União Européia (NC8). Previam-se diferentes cronogramas de liberalização, escalonados em até dez anos, para $92 \%$ do total de produtos. Cerca de 122 produtos desses, correspondentes a $1,2 \%$ do total, teriam uma preferência fixa de $20 \%$ ou $50 \%$, sem alcançar a liberalização total. Por último, para cerca de 21 produtos não havia qualquer proposta de liberalização.

Para um conjunto de produtos agrícolas, foram oferecidas cotas adicionais, em sua maioria com margem de preferência tarifária de $50 \%$, divididas em duas parcelas: a primeira, imediatamente após a assinatura do acordo; e a segunda, após a conclusão da Rodada Doha. O montante da segunda parcela, portanto, estaria condicionado aos resultados das negociações na OMC, podendo aumentar 
ou diminuir, dependendo das concessões agrícolas que fossem aceitas pela UE.

Na Tabela 1, os 249 produtos (NC8) da oferta européia contemplados com novas cotas foram agrupados em 13 categorias de bens. Para a UE, as cotas adicionais oferecidas representavam uma participação nas suas importações totais entre $0,9 \%$ e $686,3 \%$ em 2002. As menores ofertas - algumas praticamente insignificantes - foram feitas em banana (parcela da cota oferecida sobre as importações de $0,9 \%$ ), trigo (1,5\%), manteiga e gorduras de leite $(3,5 \%)$ e arroz $(4,4 \%)$. As cotas com maiores impactos nas suas compras externas foram etanol $(686,3 \%)$, carne bovina $(42,0 \%)$, carne de aves $(29,5 \%)$ carne suína $(27,5 \%)$, milho $(25,4 \%)$ e alho $(21,3 \%)$. A cota elevada para o etanol deveu-se à previsão de maior demanda futura, quando aprovadas na UE as novas regras de controle ambiental.

Para o Mercosul, os produtos com maior potencial de expansão das exportações, por ordem decrescente, são etanol (participação da cota adicional total sobre as importações originárias do Mercosul de 2.785,5\% ), arroz $(816,3 \%)$, trigo $(389,9 \%)$, alho $(87,7 \%)$, banana $(83,1 \%)$, carne de aves $(70,9 \%)$, carne bovina $(48,5 \%)$ e milho $(38,4 \%)$. Destes, destacam-se, particularmente, etanol, carne de aves e banana - produtos dos quais, entre os membros do Mercosul, o Brasil é praticamente o único exportador -, seguidos de carne bovina e milho.

Para esses produtos com oferta de cota adicional, as tarifas extracota são elevadas, variando entre $18,2 \%$ e $107,5 \%$, enquanto a amplitude da tarifa intracota é de $0 \%$ a $48,8 \%$.

\subsection{Cotas adicionais e impactos sobre a receita de divisas no Brasil}

As estimativas de ganhos para o Brasil foram calculadas para cinco principais produtos exportados ${ }^{8}$ : carne bovina $^{9}$, carne de aves, banana,

\footnotetext{
${ }^{8}$ Nas versões anteriores, foram feitos cálculos de ganhos de exportação para a carne suína, cuja exportação brasileira para o mercado europeu foi praticamente nula em 2002. Para obter essas estimativas, partiu-se da suposição de que a substituição da carne suína de outras fontes pela brasileira seria total devido ao menor preço do produto brasileiro, isto é, consideramos que as carnes de fontes diversas são homogêneas. A fim de manter a mesma hipótese de bens diferenciados para todos os produtos, não efetuamos nessa versão a estimativa de ganho do Brasil nas exportações desse bem.

${ }^{9}$ Cicowiez e Galperín (2005) estimam o ganho argentino com a cota adicional de carne bovina da UE.
} 


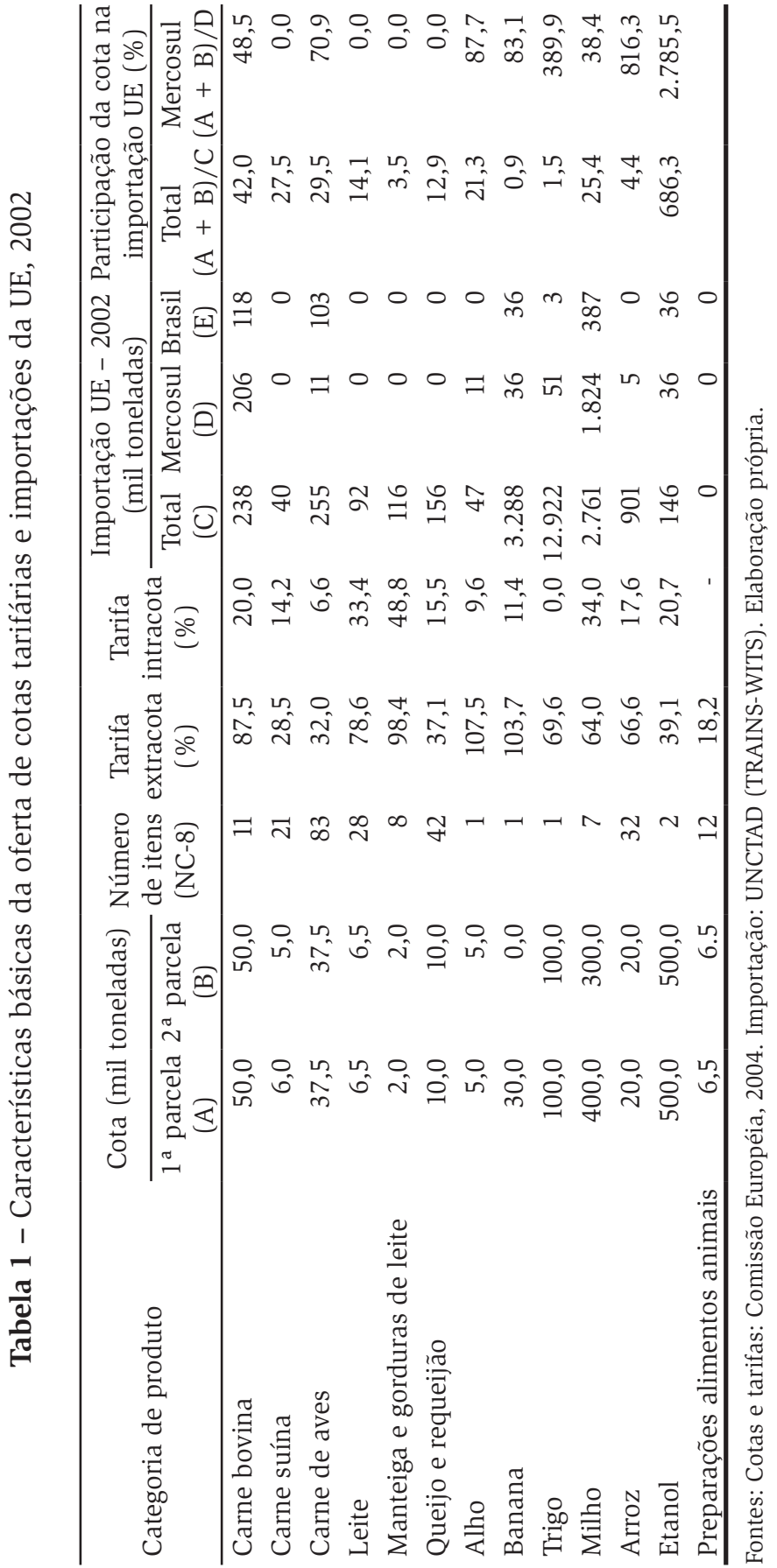


milho e etanol. Os dados de importação de 2002 foram extraídos da UNCTAD (TRAINS-WITS). As informações sobre cotas tarifárias e tarifas foram obtidas da oferta européia apresentada em maio de 2004 (COMISSÃO EUROPÉIA, 2004), considerada a melhor proposta colocada na mesa pela $\mathrm{UE},{ }^{10}$ descrita anteriormente. A metodologia de cálculo dos ganhos seguirá a análise feita na subseção 2.2. A aplicação de cada caso variará de acordo com o produto, conforme explicado em seguida.

Para cada produto, supôs-se que a parcela do Brasil na cota adicional oferecida pela UE seria equivalente à sua participação nas exportações totais do Mercosul para aquele mercado no ano analisado, e que a tarifa intracota receberia uma preferência de $50 \% .{ }^{11}$ Além disso, como o método de administração da cota ainda não tinha sido acordado, foram considerados dois cenários: o primeiro com a administração da cota pelo Mercosul; e o segundo, pela UE.

Os resultados sobre a renda da cota e o incremento das exportações, ambos divididos em duas parcelas, conforme a proposta européia, são mostrados na Tabela 2.

Para carne de aves, banana e milho, o Brasil não dispõe de uma cota tarifária, de modo que todas as suas exportações estão sujeitas à tarifa extracota. Dado que a parcela oferecida ao Brasil é inferior à quantidade das exportações brasileiras ao mercado europeu, a cota ofertada apenas substituiria as vendas anteriores, não propiciando um aumento na quantidade exportada. No entanto, a eliminação da tarifa extracota para esses produtos dentro da cota geraria uma renda extra, que pode ser apropriada pelos exportadores brasileiros, de US\$ 59 milhões para carne de aves, US\$ 19,5 milhões para banana e US\$ 11 milhões para milho (Tabela 2).

Para a carne bovina, a primeira parcela da cota adicional é inferior às importações européias desse produto provenientes do Brasil, feitas com pagamento de tarifa extracota. Dessa forma, ocorre uma substituição entre uma parcela da importação extracota e a nova cota, não gerando incremento nas exportações, mas podendo propiciar uma renda extra de US\$ 83,7 milhões. No entanto, incluindo-se a segunda parcela,

${ }^{10}$ A proposta apresentada é resultado das negociações com a UE composta por 15 países membros.

${ }^{11} \mathrm{Na}$ ausência de tarifa intracota, a redução aplica-se à tarifa vigente. 
a cota adicional total passaria a ser maior do que as importações atuais extracota. Nesse caso, o preço da carne brasileira se reduziria, ${ }^{12}$ afetando negativamente a renda da cota dessa segunda parcela, que atingiria apenas US\$ 42,2 milhões. A quantidade exportada, porém, se elevaria em US\$ 50 milhões, pela diferença entre a nova cota e as importações extracota anteriores (caso da Figura 4). No total, o Brasil poderia auferir um ganho líquido de US\$ 175,9 milhões.

Tabela 2 - Estimativas de ganhos para o Brasil (Em US\$ milhões)

\begin{tabular}{|c|c|c|c|c|c|c|c|c|}
\hline \multirow[t]{2}{*}{ Produto } & \multirow{2}{*}{$\begin{array}{c}\text { Valor } \\
\text { da cota }\end{array}$} & \multicolumn{3}{|c|}{$\begin{array}{c}\text { Renda da cota } \\
\text { administração Mercosul }\end{array}$} & \multicolumn{3}{|c|}{ Ganho de exportação } & \multirow[t]{2}{*}{ Total } \\
\hline & & a parcela 2 & parcela & Total & $1^{\mathrm{a}}$ parcela 2 & parcela & Total & \\
\hline Carne de aves & 116,9 & 29,5 & 29,5 & 59,0 & 0,0 & 0,0 & 0,0 & 59,0 \\
\hline Banana & 13,4 & 19,5 & 0,0 & 19,5 & 0,0 & 0,0 & 0,0 & 19,5 \\
\hline Milho & 17,2 & 6,3 & 4,7 & 11,0 & 0,0 & 0,0 & 0,0 & 11,0 \\
\hline Carne bovina & 175,5 & 83,7 & 42,2 & 125,9 & 0,0 & 50,0 & 50,0 & 175,9 \\
\hline Etanol & 426,4 & 19,0 & 19,0 & 38,0 & 213,2 & 213,2 & 426,4 & 464,4 \\
\hline Total & 749,4 & 158,0 & 95,4 & 253,4 & 213,2 & 263,2 & 476,4 & 729,8 \\
\hline $\begin{array}{l}\text { Total, exclusive } \\
\text { etanol }\end{array}$ & 323,0 & 139,0 & 76,4 & 215,4 & 0,0 & 50,0 & 50,0 & 265,4 \\
\hline
\end{tabular}

Fonte: Elaboração própria.

Obs.: O valor da cota tarifária, exibido na primeira coluna, corresponde à parcela do Brasil na cota adicional ofertada, a preços de exportação FOB do Brasil para a UE, em 2002.

No caso do etanol, assumiu-se que a nova legislação ambiental européia deslocará a demanda de forma suficiente para absorver a cota oferecida sem influenciar os preços. Assim, haveria um aumento de US\$ 426,4 milhões nas exportações e um ganho potencial de US\$ 38 milhões na renda da cota.

As estimativas de ganho nas exportações totais dos produtos analisados atingem US\$ 476,4 milhões, que correspondem a 63,7\% do valor da parcela brasileira das cotas adicionais oferecidas pela UE. No caso de administração das cotas pelo Mercosul, o Brasil teria um ganho adicional de US\$253,4 milhões proporcionado pela renda da cota, gerando um ganho total de divisas de US\$ 729,8 milhões.

12 Para o cálculo do novo preço, foi utilizada uma elasticidade-preço de importação de 1,12 , que corresponde a uma média simples daquelas utilizadas por Cline et al. (1979) e por Hoekman, Ng e Olarreaga (2002). 
Esses resultados sugerem que, dependendo das condições em que se enquadrem as exportações brasileiras dentro das atuais cotas tarifárias da UE, as ofertas de cotas adicionais podem gerar um aumento para as exportações brasileiras inferior ao estimado a preços correntes (coluna 1, Tabela 2). Somente com a apropriação da renda da cota, o ganho total pode se aproximar do valor da cota, o que mostra a importância, nas negociações comerciais, da definição de quem manterá o controle da cota.

Adicionalmente, uma vez que as estimativas de ganhos totais - seja utilizando-se volumes adicionais ofertados a preços correntes, seja através do cálculo com cotas tarifárias - são fortemente influenciados pelo etanol, os ganhos potenciais podem ser melhor avaliados com a exclusão desse produto. Assim, os ganhos provenientes das cotas adicionais incluindo a renda da cota cairiam de US\$ 728,5 milhões para US $\$ 265,4$ milhões. O ganho nas exportações passaria de US\$ 476,4 milhões para apenas US\$ 50 milhões.

Com o emprego dos modelos descritos para a avaliação das cotas tarifárias, a aplicação feita com base na oferta da UE, excluindo-se o produto etanol, indica que os ganhos em divisas para o Brasil dependerão fundamentalmente de quem administrará a distribuição da cota. Se for o Mercosul, o ganho será de US\$ 265,4 milhões. Se for a UE, será de US\$ 50 milhões.

\section{Considerações finais}

Na maioria dos produtos agrícolas, a proteção é dada pela cota tarifária, composta por três instrumentos: a tarifa intracota, geralmente reduzida, aplicada às importações até um determinado montante - a cota - e a tarifa extracota, usualmente elevada, que incide sobre a parcela importada acima da cota. Desses instrumentos, apenas um, determinado pela demanda, efetivamente limita as importações, sendo os demais redundantes. Além disso, dependendo do método de administração da cota, a renda dela pode ser auferida pelo país exportador ou pelo país importador.

Nas negociações comerciais, um procedimento comum é a oferta de cotas adicionais que permitem ampliar as importações com tarifa redu- 
zida (intracota), induzindo à percepção de que ocorrerá um aumento efetivo na quantidade exportada equivalente à cota adicional concedida. Esse procedimento, contudo, ignora a substituição das exportações atuais pelas cotas adicionais e também não considera o impacto sobre a renda extraordinária proporcionada pela cota.

Neste trabalho, procurou-se estimar os ganhos para o Brasil proporcionados pela oferta de cotas adicionais pela UE para cinco produtos: carne bovina, carne de aves, banana, milho e etanol. No caso de administração da cota pelo Mercosul, os resultados indicam um aumento de US \$ 728,5 milhões na receita de divisas, sendo US\$252,1 milhões pela apropriação das rendas das cotas e US\$ 476,4 milhões pelo incremento nas exportações. O resultado é bastante próximo do valor da cota oferecida para esses produtos a preços correntes. No entanto, se o controle das cotas for realizado pela UE, o ganho do Brasil decorrerá exclusivamente do aumento das exportações, atingindo apenas 63,7\% do valor da cota citada. Excluindo-se o etanol, o aumento na receita de divisas seria de US\$264,1 milhões (US\$ 214,1 milhões de renda das cotas e US\$ 50 milhões de receita de exportações).

Tais resultados mostram que a desconsideração dos elementos que explicam o funcionamento dos regimes de cotas tarifárias e das condições de demanda dos diferentes produtos pode introduzir um viés na estimação dos ganhos potencialmente gerados pela concessão de cotas adicionais nas negociações comerciais de produtos agrícolas.

\section{Referências bibliográficas}

CICOWIEZ, M.; GALPERÍN, C. Análisis cuantitativo de cambios en las cuotas arancelarias: el caso de las exportaciones de carne vacuna a la UE. Revista Del CEI Comercio Exterior e Integración, Buenos Aires, n. 4, p. 107-128, nov. 2005.

CLINE, W. R.; KAWANABE, N.; KRONSJO, T. O. M.; WILLIAMS, T. Trade negotiations in the Tokyo round: a quantitative assessment. Washington, D.C.: Brooking Institution, 1978. 322 p.

COMISSÃO EUROPÉIA. Oferta da UE de acesso a mercado. Disponibilizado pelo Ministério das Relações Exteriores do Brasil. Maio, 2004. 
GORTER, H.; HRANAIOVA, J. Quota administration methods: economics and effects with trade liberalization. In: INGCO, M. D.; NASH, J. D. (Eds.). Agriculture and the WTO: creating a trading system for development. Washington, D.C.: World Bank and Oxford University Press, 2004. 387p. ; INGCO, M. D.; IGNÁCIO, L. Market access: economics and the effect of policy instruments. In: INGCO, M. D.; NASH, J. D. (Eds.). Agriculture and the WTO: creating a trading system for development. Washington, D.C.: World Bank and Oxford University Press, 2004. 387p.

HOEKMAN, B.; NG, F.; OLARREAGA, M. Eliminating excessive tariffs on exports of least developed countries. World Bank Economic Review, Washington, D.C, v. 16, n. 1, p. 01-21, Jun. 2002.

KUME, H.; PIANI, G.; MIRANDA, P.; CASTILHO, M. Acordo de livrecomércio Mercosul-União Européia: uma estimativa dos impactos no comércio brasileiro. Rio de Janeiro: IPEA, nov. 2004. 15 p. (Texto para discussão, n. 1.054).

SKULLY, D. W. Liberalizing tariff-rate quotas. In: Burfisher, M. E. (editor). Agricultural policy reform in the WTO - the road ahead. Washington, D.C: Economic Research Service/U. S. Department of Agriculture, May 2001. (Agricultural Economic Report, n. 802). cap. 3, p. 59-67.

UNCTAD. Trade Analysis and Information System (TRAINS): base de dados. In: WORLD BANK/UNCTAD. World Integrated Trade Solution (WITS): base de dados. Disponível em < http://wits.worldbank.org/ > . Acesso em: 04 de mar. de 2006.

UNITED STATES TRADE REPRESENTATIVE. US-Chile Free Trade Agreement Final Text. Disponível em: < http://www.ustr.gov/World_Regions/Americas/Section_Index.html > . Acesso em: 10 maio 2006.

Recebido em dezembro de 2006 e revisto em fevereiro de 2007 